\title{
A Management and Decision Making Resource for Agricultural Education in India
}

\author{
Shashi Dahiya \\ IASRI, Library Avenue, \\ Pusa, New Delhi-110012
}

\author{
Pal Singh \\ IASRI, Library Avenue, \\ Pusa, New Delhi-110012
}

\author{
R. C. Goyal \\ IASRI, Library Avenue, \\ Pusa, New Delhi-110012 \\ Soumen Pal \\ IASRI, Library Avenue, \\ Pusa, New Delhi-110012 \\ R. B. Grover \\ IASRI, Library Avenue, \\ Pusa, New Delhi-110012
}

\author{
Alka Arora \\ IASRI, Library Avenue, \\ Pusa, New Delhi-110012
}

\begin{abstract}
Agriculture Education has been viewed in many developing countries as a significant contributor to sustainable development and poverty alleviation. With the development of Agricultural Science and technology the quantity of information and data collected and processed for the planning and management of Agricultural Education activities has been constantly on the increase. Also, the size and complexity of the Agricultural Education system continue to expand as the population and economy grows. With this growing pressure of information revolution and knowledge explosion, the informational requirements of planning and management of Agricultural Education are tremendous. It is important for the decision-makers to have reliable and relevant information for decision-making in the process of educational planning and management in agriculture. This paper presents a solution to this problem with the development and deployment of a National Information System on Agricultural Education Network in India (NISAGENET).
\end{abstract}

General Terms: Agricultural Education, Information System,Web Technology

\section{Keywords}

ICAR, Agricultural Education, MIS, NISAGENET, AU, Central Universities

\section{INTRODUCTION}

Educational planners and administrators have been witnessing a steady growth in the amount and variety of information that has been collected and made available to them. Information Technology (IT) solutions had always been very effective and successful in such situations. Management Information System(MIS) can be used for the management of such exponentially growing information. MIS is commonly used to refer to the group of information management methods tied to the automation or support of human decision making. They provide information that is needed to manage organizations efficiently and effectively. The advantage of using IT is that time-consuming data management tasks can be performed by means of this technology and time can thus be devoted instead to communicating and informing, to the processing of information and the production of knowledge. An MISwas needed at the national level where all institutions contributing under Agricultural Education in India were to be managed. Indian Agricultural Statistics Research Institute (IASRI) took a step ahead in this direction, by developing and deploying a system -National Information System for Agricultural Education Network (NISAGENET) for the management of Agricultural Education in India. NISAGENET was previously developed and implemented using Active Server Pages (ASP) technology [Sharma et al. (2006)]. With the increasing demand for more decision support modules on Agricultural Education, need was felt to further strengthen and maintain the NISAGENET. It was also Observed that the system needs to be rebuilt on a latest robust and more secure technology so that it remains compatible with higher versions and upcoming web technologies [Farooqi et al. (2011).]. Thus development of a new version of NISAGENET started using .NET framework.

In NISAGENET, broadly Information on General \& Academic information of the Universities, Infrastructural facilities, Budget provision, Manpower employed R\&D activities of each and all the State Agricultural Universities (SAU) and Deemed universities of Indian Council for Agricultural Research (ICAR) is made available. The system has been designed, developed and being maintained at the Indian Agricultural Statistics Research Institute (IASRI), New Delhi. There are 63 participating organizations of NISAGENET, engaged in Agricultural Education in India. These organizations are broadly distributed amongst State Agricultural Universities, 


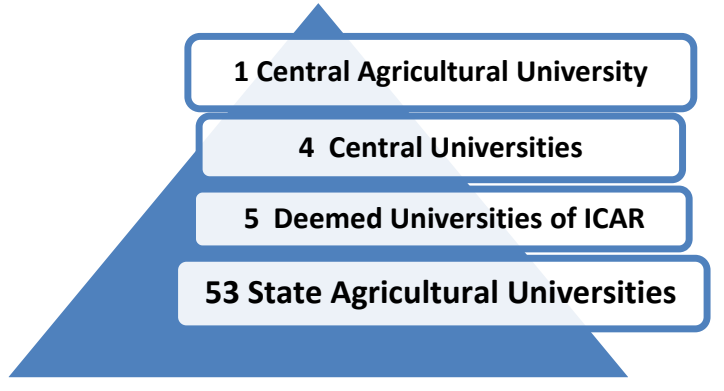

Fig.1: Organizational Structure of NISAGENET

Deemed Universities of ICAR, Central Universities and Central Agricultural Universitiesas depicted in Fig.1.The NISAGENET is available centrally at the IASRI site at the web address: http://nisagenet.iasri.res.in/. The data entry and updation can be done online by directly accessing the Data Management Module of NISAGENET from the Central Server. In order to provide the realistic and up-todate reporting through NISAGENET, it is essential to update and validate the existing data and regular updating from all the SAU's along with their constituent/affiliated colleges. Under NISAGENET, 63 universities and 527 affiliated and constituent colleges are providing data into NISAGENET.

\section{DESIGNof NISAGENET}

\subsection{SystemDesign}

An information system for strategic planning is more elusive than other systems therefore certain degree of structure is a prerequisite for developing such information systems [Arora et al. (2005)]. Information coverage in NISAGENET system is vast and it contains information on

all parameters of a University / Affiliated College from its Students to faculty, Budget, Infrastructural details, Courses, Research and Development, Manpower, HRD and other general details. While designing the system hierarchical approach has been used keeping in mind that attributes covered are large in number and all the attributes are relevant for all universities. System has been designed into two main modules i.e. Data Management and Management Reports. Data management module deals with organization of data and report module provide information on collected parameters to managers at different levels[Dahiya. et.al (2004)]. Keeping in view the security and consistency of data, the Data Management Module has got limited access to only the authorized users and these are authenticated Nodal officers at the University/ College level. Nodal officers have the privileges to add, update and view the information. Nodal officers update the information on the regular basis. The Reports module is accessible to all users of the system.For the purpose of proper data storage, management and reporting, NISAGENET has been distributed amongst seven modules/ schedules. Each module/ schedule is based on some important activity of the University/College. The modules are:Academic, Infrastructural facilities, Budget provision, Faculty and other Manpower, Research \& Development, Human Resource Development and General Information.

\subsection{Software Design}

It is a process of problem solving and planning for a software solution. It includes Data Structures, Software Architecture, Interface Representation and Procedural Details. NISAGENET has been designed as a web application which can be accessed for updating and reviewing from any node on the internet through any web browser. The Thin - client 3-tier client server architecture has been used for the development of the system. The Data Access tier was developed using MS SQL-Server at the backend. The Business Logic tier was developed using C\# in ASP.NET. The User Interface or Presentation Tier contains web pages where data is presented to the user or input is taken from the user.The main advantage of 3-tier architecture is to separate the presentation layer from data access layer. There is no need to write any function to communicate with database in presentation layer; all the required functions for communication with database are available in DataAccessLayer. Therefore, at presentation layer there is focus on the information that is being presented in front of the user.

\subsection{Database Design}

The term database design can be used to describe many different parts of the design of an overall database system. The relational model of database design has been used for NISAGENET. Relational Data Base Management system (RDBMS) offers the benefits of easy access to all data, complete flexibility in database design, reduced data storage and redundancy, and is easier to maintain [Emasei et al. (1994)]. The SQL Server was used for the database design, access and management. The database tables were designed following the rules of normalization and consequently the redundancy was minimized. A unique University Id and corresponding College Id were generated for all the Universities and their consequent/affiliated colleges. The Entity Relationship Model has been used to design the database of NISAGENET. The following four steps were adopted in designing a database using the entityrelationship model:

(1) The entity sets and the relationship sets of interest were identified

(2) The semantic information in the relationship sets were identified

(3) The value sets and attributes were defined

(4) The datawas organized into entity/relationship relations and the primary keys were decided.

The results of the all the four steps of database design are expressed in an entityrelationshipdiagram of NISAGENET as shown in Fig. 2.With the explicit concepts of entity and relationship, the entity-relationship model is useful in understanding and specifying the constraints for maintaining the data integrity. 
The Entity- Relationship diagram of NISAGENET describes all these entities and the attributes considered for data storage and management.

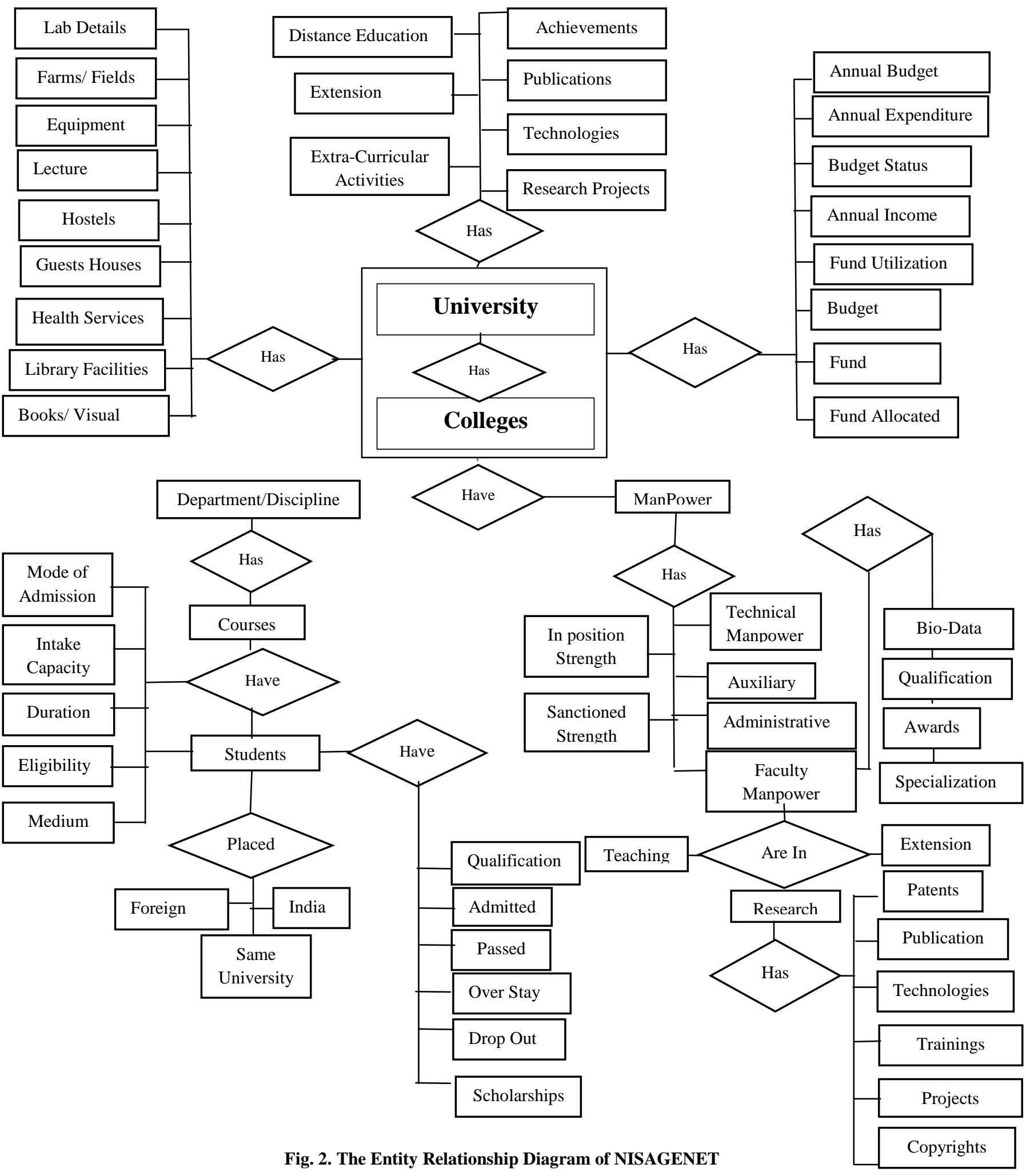




\section{RESULTS AND DISCUSSION}

The size of the NISAGENET database is very big as the data is entered on almost each and every aspect of a university/ college.Also new data keeps on coming in NISAGENET, so the data management and maintenance tasks are very crucial. For data management, data entry/ updation forms have been designed and developed for entering the data related to all attributes of a university/college, schedule wise.There are 6 schedules viz.
Academic, Infrastructure, Budget, Manpower, Faculty, Research and Development and Others respectively.Also, a data status report (Fig.3)has been designed to check the status of data under each schedule for a particular university during a particular year.The data for each university and affiliated/ constituent colleges is available under each schedule. So the reports are also available under each schedule.

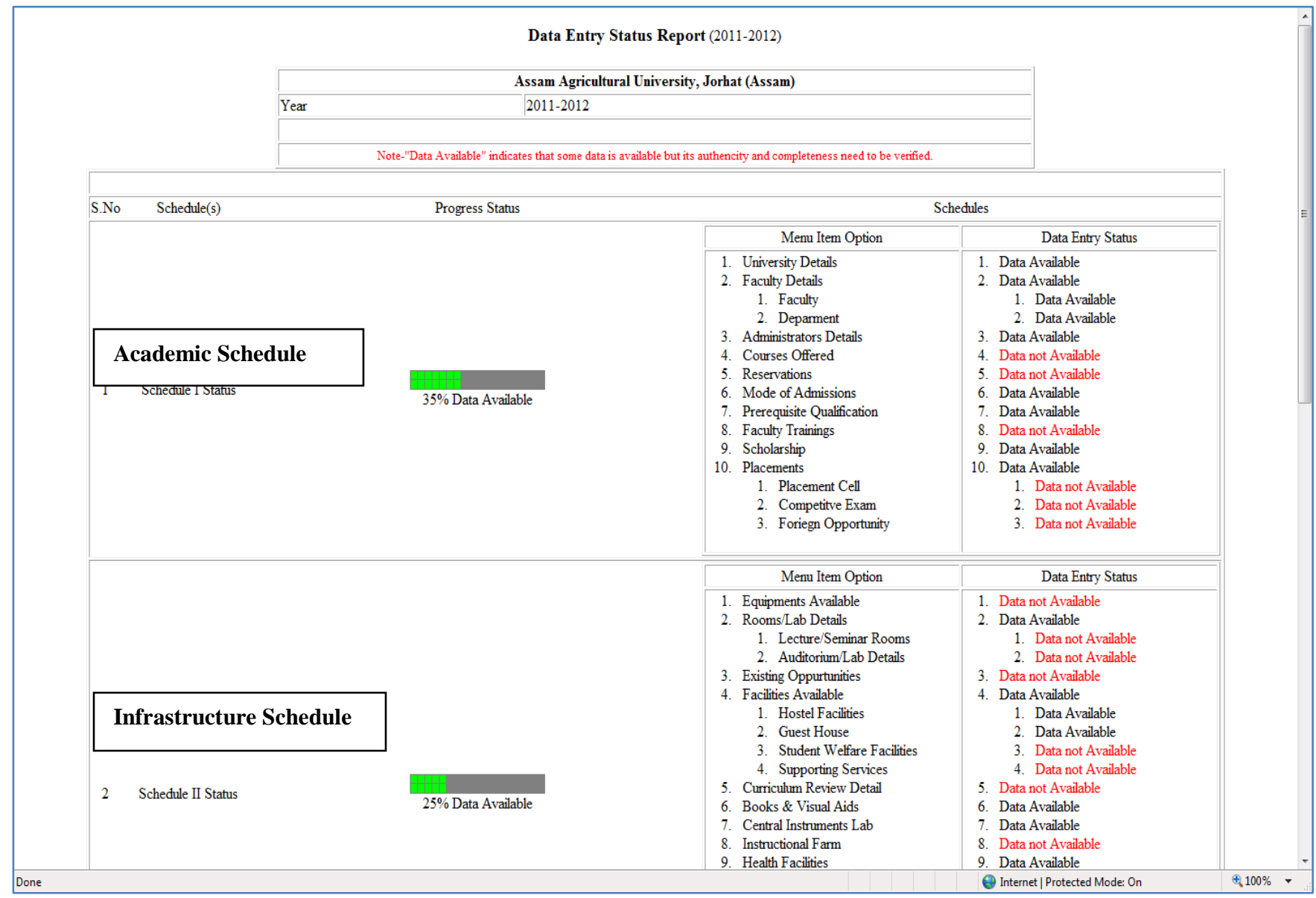

Fig. 3. The Data Status report of a University for Two Schedules

Further the universities and affiliated/ constituent colleges have been distributed under differentstates and disciplines, so the reports can be generated state wise, discipline wisealso. The State wise university distribution and
Discipline wise university and affiliated/ constituent college's distribution in NISAGENET is shown in the Fig.4 and Fig.5.respectively. 


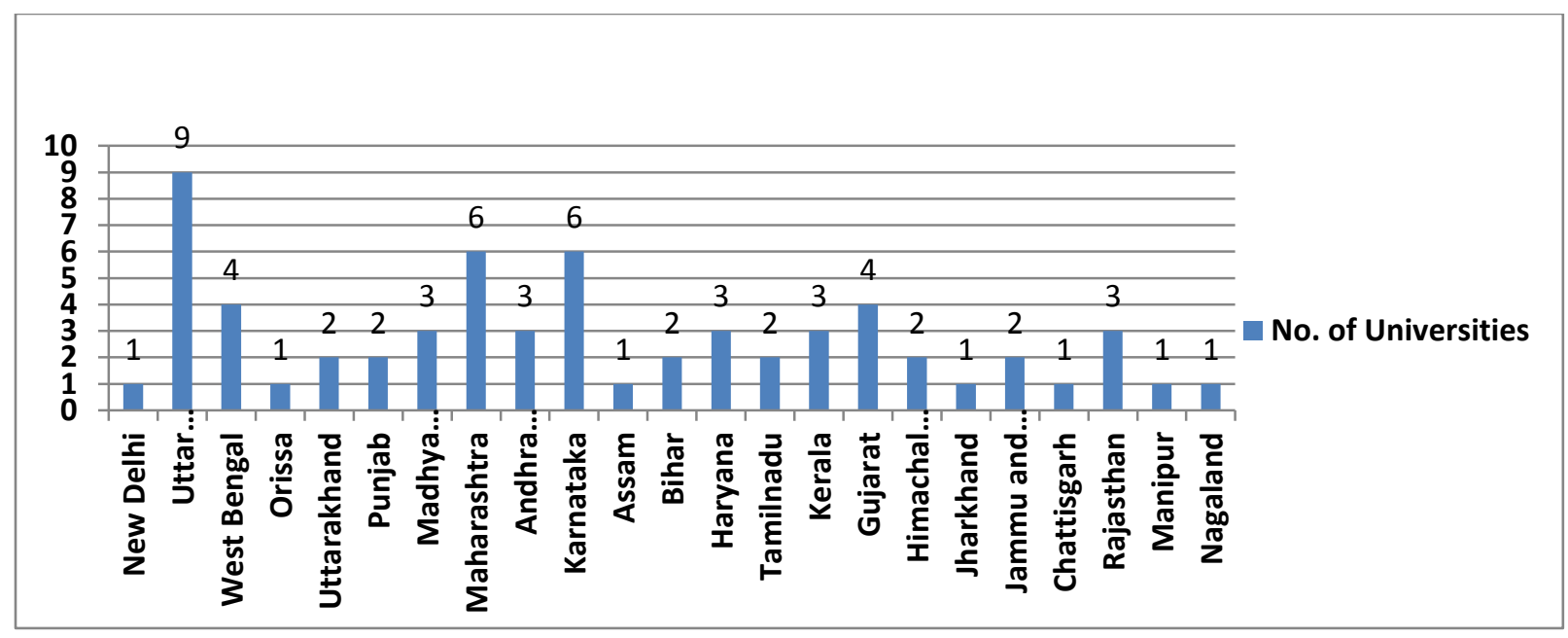

Fig.4. Distribution of Agricultural Universities under Different States of India

(Source: NISAGENET)
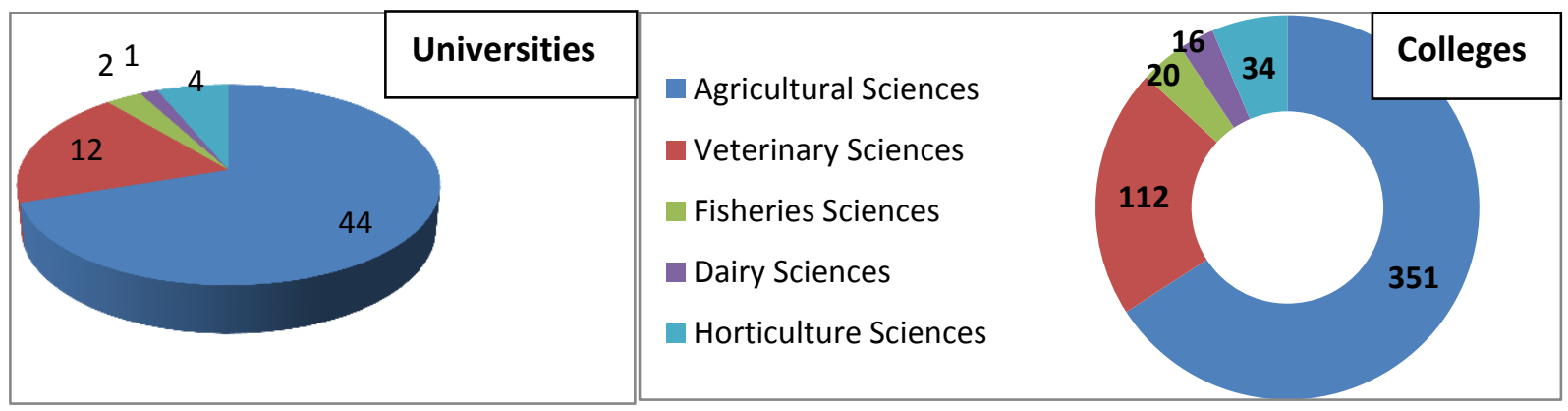

Fig.5. Distribution of Universities and Collegesunder Major Disciplines(Source: NISAGENET)

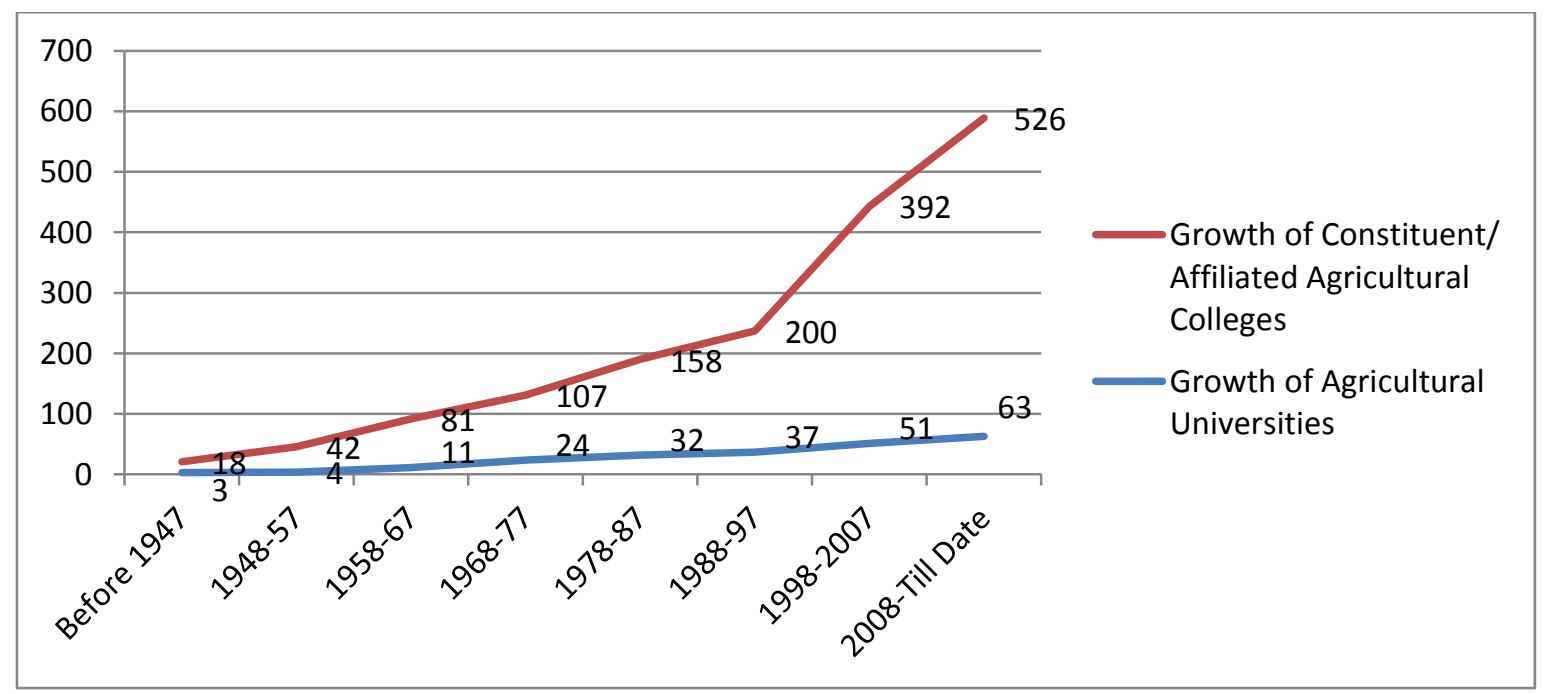

Fig. 6. Growth of Agricultural Universities and Colleges in India(Source: NISAGENET) 
From the data available in NISAGENET, the positive trend of establishment of agricultural Universities in India during different decades before and after independence has been shown in Fig. 6. The graph shows a positive growth trend for AU's, which has started from a nominal 3 before independence to 63 post independence. This trend has not stopped yet and some new AU's are also under establishment and some are in the phase of planning and initiation. The trend of establishment of Agricultural Colleges is highly positive and it shows a steep growth pattern from 200 in 1988-97 to 526 Agricultural colleges till date.Amongst 63 AU's, 44 are agricultural universities, 12 are veterinary universities, 2 are fisheries universities and 5 are horticultural universities.

\section{CONCLUSIONS}

NISAGENET is a platform to capture the present agricultural education status throughout the country in an organized way. It is a kind of system which assembles nationwide information on agricultural education, synthesizes the data and produces them in a meaningful way so that the overall agricultural education scenario in India becomes visible and comprehensive. From the rich data available in NISAGENET, several useful conclusions can be drawn by the managers and various important policy decisions can be taken for the upliftment of agricultural education in India. It contains almost all relevant data on General \& Academic information of the Universities, Infrastructural facilities, Budget provision, Manpower employed R\&D activities of each and all the State Agricultural Universities (SAU) and Deemed universities of Indian Council for Agricultural Research (ICAR). Being web-based, the system facilitates a more efficient dissemination of data than was previously possible. It uses well-known .NET Technology to allow users to extract and view data interactively and in a variety of user friendly ways. It provides the on-line data entry and updation facilities, search facilities, a variety of detailed and consolidated reports at University and College Level and it also provide an overview of data available on the prescribed attributes chosen online by the user. These reports are able to serve various information needs of different user groups. The NISAGENET system act as a tool for decision making for agricultural education, research, development and manpower planning.
Continuous updating and addition of new reports and modules in the system will provide improved decision support to Managers of ICAR.

\section{REFERENCES}

[1] Dahiya, S., Singh, B., Arora, A., and Farooqi, M.S. (2004). Web based Personnel Management Information System for Indian Council of Agricultural Research (ICAR). Journal of Indian Society of Agricultural Statistics, 58(2), 244-252.

[2] Farooqi, M.S., Singh, B., Arora, A., Dahiya, S. (2005). PERMISnet : e-solution for ICAR. Agricultural Extension Review, 17(3), 3 - 5.

[3] Arora, A., Singh B., Dahiya S., Farooqi, M.S. (2005). Planning and Distribution of ICAR Manpower through Personnel Management Informatiion System (PERMISnet).Journal of Indian Society of Agricultural Statistics. , 59(2), 141-145.

[4] Sharma, A., Goyal, R.C., Gupta, V.H. and Grover, R.B. (2006). Design and on-line management of database on Indian Agricultural Education System.Journal of Indian Society of Agricultural Statistics, 60(3), 155-161.

[5] Elmasri, Ramez and Navathe, B. Shamkant (2006).Fundamentals of Database Systems. AddisonWesley Publishing Company.

[6] Blaya, J.A., Shin, S.S., Yagui, M.J.A., Yale, G., Suarej, C. Z., Asencios, L., Cegielski, J.P., Fraser, H.S.F. (2007). A web-based laboratory information system to improve quality of care of tuberculosis patients in Peru: Functional Requirements, implementation and usage statistics. BMC Medical Informatics and Decision Making. 7(33), 1-11.

[7] Arora, A., Sharma, S.D., Malhotra, P.K. and Goyal. R.C. (2008). Agricultural Statistician Network (ASN). Journal of Indian Society of Agricultural Statistics. , 62(1), 49-55.

[8] Farooqi, M.S., Arora, A., Dahiya, S., Rai, A., Singh, B., (2011).PERMISnet-II: Personnel Management Information System Network-II for the Indian Council of Agricultural Research. Journal of Indian Society of Agricultural Statistics , 65(1), 105-113. 